\title{
A Note on Pacific Decadal Oscillation, El Nino Southern Oscillation, Atlantic Multidecadal Oscillation and the Intertropical Front in Sahel, Africa
}

\author{
Luiz Carlos B. Molion ${ }^{1}$, Paulo Sérgio Lucio ${ }^{2}$ \\ ${ }^{1}$ Instituto de Ciências Atmosféricas, Universidade Federal de Alagoas, Maceió, Brazil \\ ${ }^{2}$ Programa de Pós-Graduação em Ciências Climáticas, Universidade Federal do Rio Grande do Norte, Natal, Brazil \\ Email:1cmolion@gmail.com,pslucio@ccet.ufrn.br
}

Received March 6, 2013; revised April 10, 2013; accepted April 18, 2013

Copyright (C) 2013 Luiz Carlos B. Molion, Paulo Sérgio Lucio. This is an open access article distributed under the Creative Commons Attribution License, which permits unrestricted use, distribution, and reproduction in any medium, provided the original work is properly cited.

\begin{abstract}
The advance and retreat of the Sahara Desert are repetitive in decadal time scale and have significant social impact in the Sahel. This climate variability, unique in the world, results from the irregular motion of the Intertropical Front (ITF) - a discontinuity originated from the convergence of two air masses over the African continent of distinct thermodynamics characteristics, moisture concentration in particular - that is the large-scale mechanism responsible for the rainfall over the Sahel. The ITF displacement and associated rainfall seasonal totals were analyzed considering the Pacific Decadal Oscillation (PDO) warm (WP) and cold (CP) phases. It was apparent that the frequency and intensity of El Niño (La Niña) events was higher in the warm (cold) phase as compared to the cold (warm) phase. Rainfall composites for El Niño and La Niña events were made for each PDO phase, a total of four composites. It was found that the rainfall was above normal during the CP La Niña events, that is, the ITF was displaced northward, whereas the rainfall was restricted to Western Sahel in the CP El Niño events. Rainfall was reduced during the PDO WP in both El Niño and La Niña composites. Considering that PDO has entered a new CP since 1999, it is possible that the La Niña events may behave similarly to the ones last CP, wetting the Sahel when they occur within the next 20 years. But, it is brought out the possibility that Pacific Decadal Oscillation (PDO) is not a regular physical oscillation and the duration of its phases may not be predictable, being dependent of large magnitude seismic events, which are rare and random. The important point, however, is that the Pacific sea surface temperature (SST) pattern, once established and recognized, may remain for a relative long (decades) period. Its SST pattern, due to its large area extension, modulates the global climate and its impacts on the regional climate.
\end{abstract}

Keywords: Sahara Desert; Sea Surface Temperature; Variability

\section{Introduction}

Human activity planning, in particular agriculture and energy generation, requires climate outlook with sufficient leading time, 5 to 10 years ahead, so its results can be beneficial for society. This need is highly apparent in the Sahel, a latitudinal land strip of about 300 to $400 \mathrm{~km}$ wide, subjected to north-south Sahara Desert border displacement, with consequent social and economical disturbances. The advance and retreat of the desert are repetitive in decadal time scale. This climate variability, unique in the world, results from the irregular motion of the Intertropical Front (ITF), a discontinuity originated from the convergence of two air masses over the African continent usually mistaken as the Intertropical Convergence
Zone (ITCZ). However, the thermodynamic characteristics of ITCZ over the Eastern Atlantic Ocean differ considerably from the ITF ones since their geneses are different. The ITCZ is formed by the convergence of the northeastern and southeastern trade winds, two warm and moist air masses that flow off the Atlantic subtropical anticyclones towards equatorial latitudes in both hemispheres. In its annual cycle, the ITCZ has a meridional displacement between $10^{\circ} \mathrm{N}$ and $3^{\circ} \mathrm{S}$ approximately. The ITF, on the other hand, results from the convergence of a dry air mass flowing off the North African anticyclone and a southwestern warm and humid air mass which originates off the South Atlantic anticyclone. As it crosses the equator, this air stream is shifted rightwards, becom- 
ing southwesterly winds and transporting moisture into the continent. The equatorial thermal low associated with ITF over the continent is deeper and more intense than ITCZ one and its thermodynamic properties differ remarkably, moisture concentration in particular [1]. The ITF annual latitudinal displacement is larger than that of the Atlantic ITCZ, reaching $20^{\circ} \mathrm{N}$ commonly during the North Hemisphere summer.

A phenomenon that is characterized by low frequency variability and, in principle, can be used for qualitatively climate outlook, one or two decades ahead, is the Pacific Decadal Oscillation (PDO). It was described by [2] as being a long lived El Niño-Southern Oscillation (ENSO) episode. The ENSO phases, El Niño being the warm phase and La Niña the cold one, last 6 to 18 months each, of a total of 3 to 4 years for a complete cycle. The PDO, on the other hand, presents a cycle of 50 to 60 years, each phase lasting 25 to 30 years. The PDO cold phase is characterized by negative sea surface temperature (SST) anomalies extending throughout the Tropical Pacific and along the coast of North and South America and positive SST anomalies in the extratropics, whereas the warm phase has opposite SST pattern (Figure 1).

\section{Material and Methods}

The 20th century SST data reconstruction suggests that PDO underwent two distinct warm phases, one between 1925 and 1946 and another between 1977 and 1998, and at least one cold phase between 1947 and 1976 (e.g., [2]). Considering that the atmosphere is heated by its lower boundary, that is, the Earth's surface that the Pacific Ocean occupies $35 \%$ of this surface and, in addition, that each PDO phase lasts a long time period, this oscillation must impose a long lasting sign on the global climate that should be detected in climate diagnostics studies. The hypothesis formulated here is that the Pacific Ocean, and its PDO, be one the main internal global climate system controllers in the decadal time scale and that this oscillation may explain an expressive part of the Sahel climate variability and may be used for decadal climate forecasting of this region.

However, looking at Figure 2 closely, it is apparent that the phase shifts, from warm to cold in 1946, and from cold to warm in 1976, were relatively sudden. Considering that the PDO physical causes are not known and that oceans heat content temporal changes are very slow due to their large heat capacity, that is they tend to warm and cool slowly, these PDO jumps bring concern and make one reflect and question if the phenomenon is actually a semi-regular physical oscillation or if it is a mere artifact resulting from the statistical analysis. Could these sudden shifts be provoked, for instance, by tectonic plate displacements, generating tsunamis or internal ocean wa- ves, redistributing heat globally and changing SST patterns? If so, then PDO would be questionable as a basis for decadal climate prediction.

Coincidentally, on April 1st 1946, there was an intense earthquake in the Aleutian Islands, south of Alaska. According to the US Coastal Guard, it generated a $35 \mathrm{~m}$ high tsunami that propagated at speed about $800 \mathrm{~km} / \mathrm{h}$, reached Hawaii with waves 10 to $12 \mathrm{~m}$ high and killed more than 160 people, due to the fact that Hawaii didn't have tsunami warning at that time. The wave rode the whole Pacific Ocean. In that time of the year, the sea temperatures near Alaska are below $4{ }^{\circ} \mathrm{C}$. Could this tsunami have been the cause of PDO shift to the cold phase? Similarly, on July 28th 1976, an earthquake of 8.6 magnitude in the Richter scale occurred in the western side of the Pacific Plate, a region known as the Pacific warm pool. This quake reached the city of Tangshan, China, causing more than 250 thousand deaths. Could this quake have produced a wave that spread warmth throughout the Pacific, made PDO jump into the warm phase, changing the general circulation of the atmosphere? There are other details that deserve consideration, for example, the attempt to return to the warm phase in 1957 (Figure 2), that coincided with the Benzymianny volcano eruption, Kamchatka Peninsula (Russia) in 1956, an eruption rated VEI 5. In [3] is hypothesized that large volcanic eruptions, with large sulfur dioxide content, may cause global climate cooling and trigger El Niños. The volcanic aerosols would increase the planetary albedo, reduce the heating of the tropical continents, thereby reducing the horizontal pressure gradient that, in turn, would weaken the trade winds and the upwelling at South American coast. However, this shift may have been frustrated by the 9.5 magnitude earthquake that occurred in Chile on May 22nd 1960, which generated a 25 meter high cool water tsunami and travelled the entire Pacific. It is possible, thus, that PDO is a random oscillation, caused by high magnitude tectonic events, and that its phases may not have definite time periods. However, considering that gigantic earthquakes, and associated tsunamis, are not frequent, once the SST pattern changes, it may remain for a time longer than an ENSO event in one particular state, long enough to change the atmospheric pressure and wind fields patterns due to coupling of the atmosphere and the new oceanic surface conditions through air-sea interaction.

Independently of its physical causes, the long lasting mean Pacific SST pattern affects the global climate and changes the frequency and magnitude of the ENSO events. Based on the time series of the Multivariate ENSO Index (cf. [4]) and the analysis of the Climate Prediction Center (CPC/NCEP/NOAA) data set $[3,5]$ pointed out that the La Niña events were more frequent and more intense than the El Niño episodes during the PDO cold 


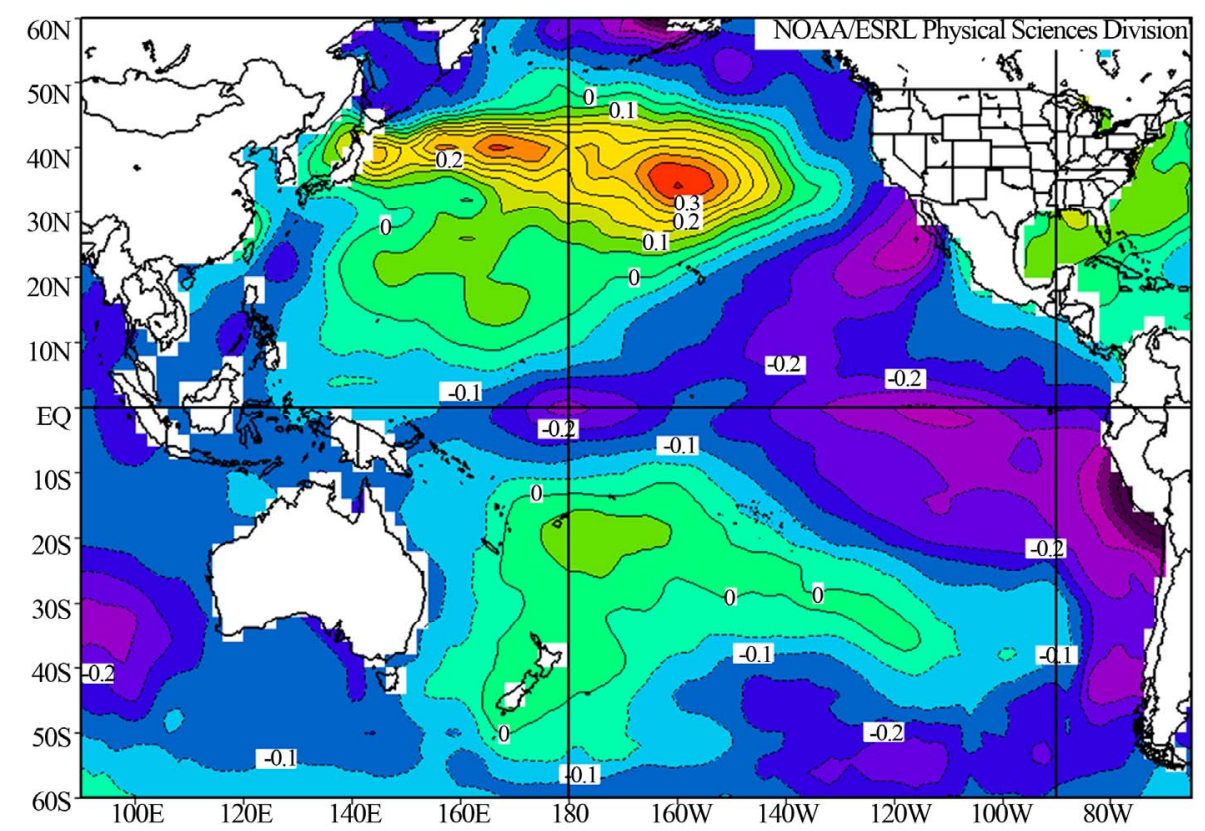

(a)

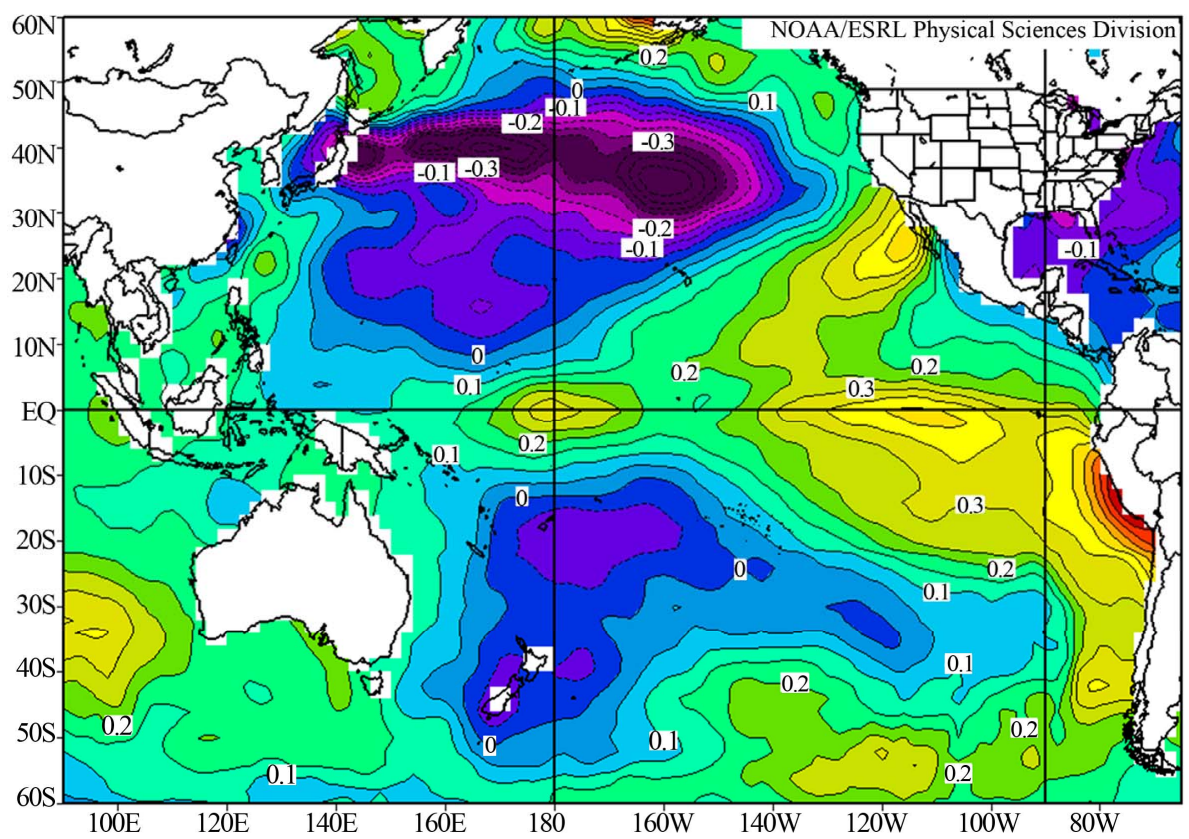

(b)

Figure 1. The Pacífic decadal oscillation (a) cold and (b) warm phases.

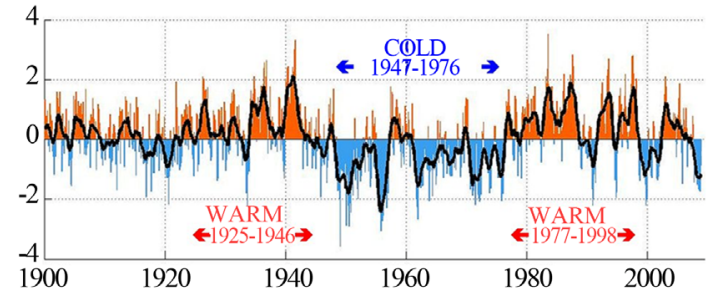

Figure 2. The PDO time series index (adapted from Mantua et al., 1997). phase. The PDO cold phase El Niño events were of short duration, lasting 6 to 9 months, and relatively weak. On the other hand, during the PDO warm phase, El Niño events were more frequent, intense, with more severe negative impacts and lasted longer than the cold phase correspondents and the La Niña frequency was smaller (Figure 3). This frequency difference, per se, may characterize a climate change from 1976 on.

El Niño and La Niña events had distinct impacts on 


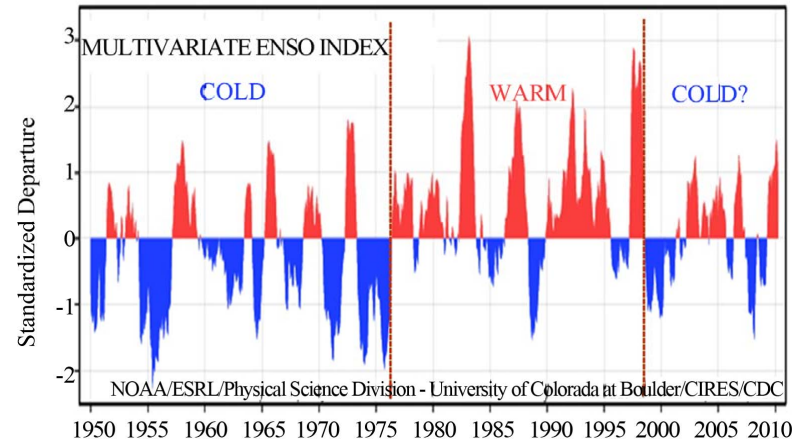

Figure 3. The multivariate ENSO index (adapted from [2]). the regional climate, depending on the PDO phase they occurred. As an example, the ENSO impacts on the Sahel rainfall were analyzed. In Figures 4 and 5, the rainfall anomalies for the period July-September were shown for the PDO cold and warm phases respectively. The period of the analysis was 1950-1999. The data were taken from the Earth System Research Lab (ESRL/PSD/NOAA) website. The rainfall data is from a gridded dataset $0.5^{\circ} \times$ $0.5^{\circ}$ lat/long resolution prepared by the University of Delaware. The ENSO events used for the composites are listed in a table found in the CPC/NCEP/NOAA website from [5]. Only the ENSO events that persisted through-

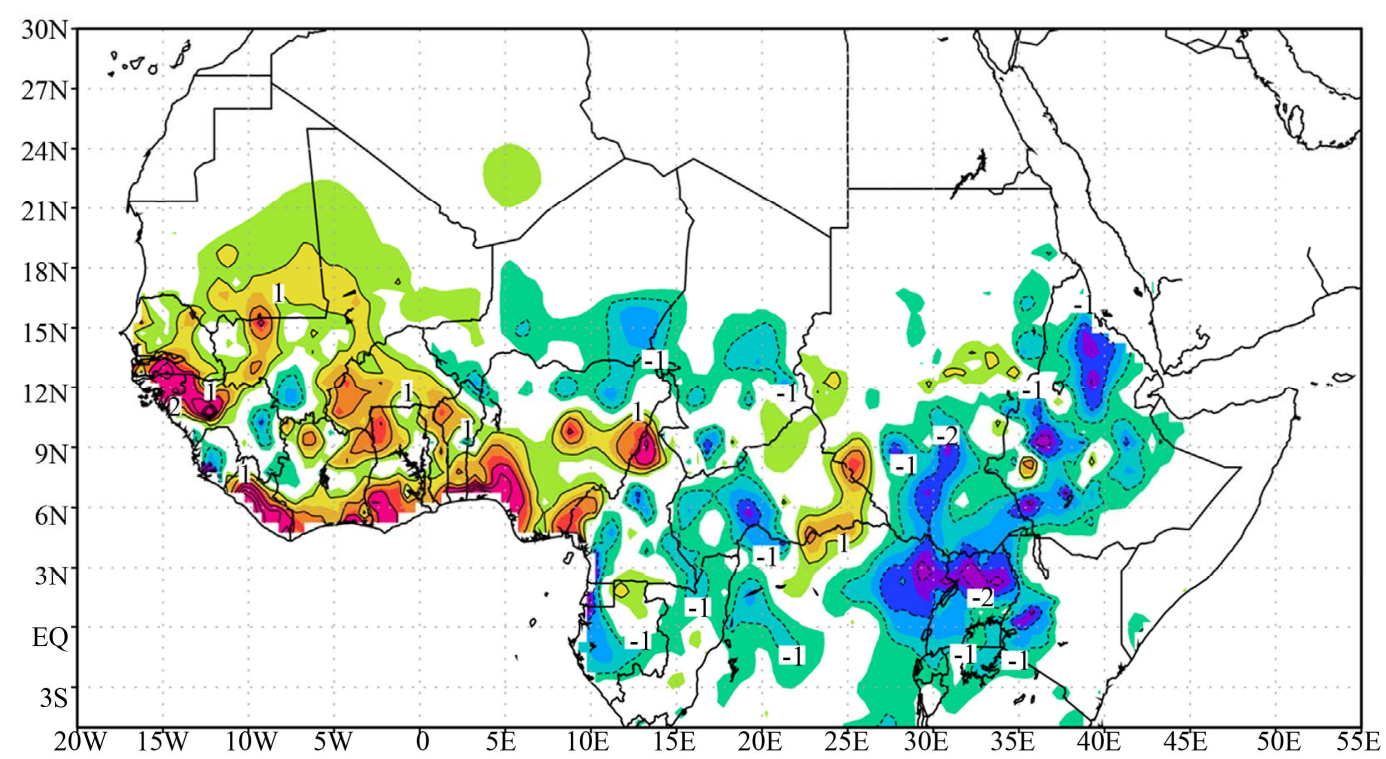

(a)

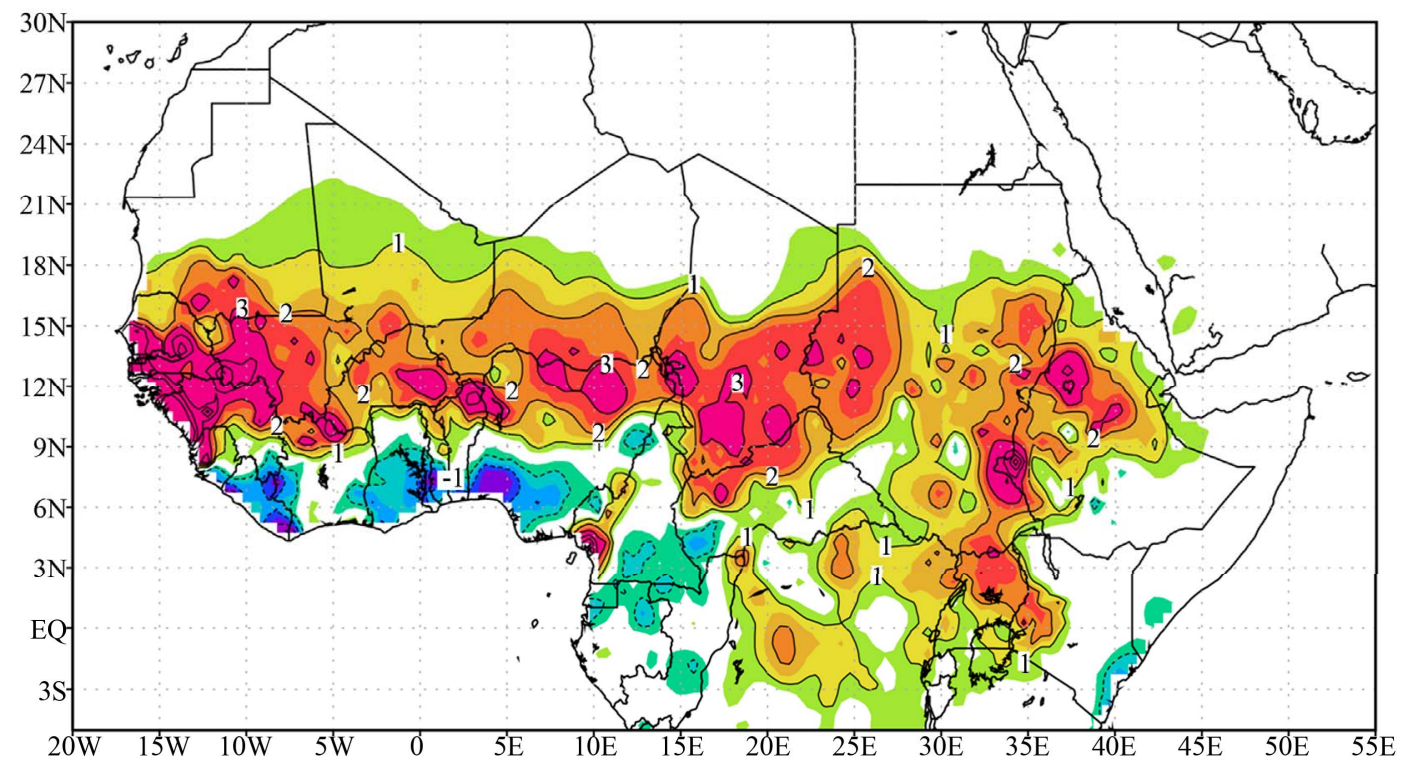

(b)

Figure 4. Composites of Jul-Sep rainfall deviations from the 1950-1999 mean for (a) El Niño e (b) La Niña, during PDO cold phase (CP). Data source: UDEL (ESRL/PSD/NOAA). 


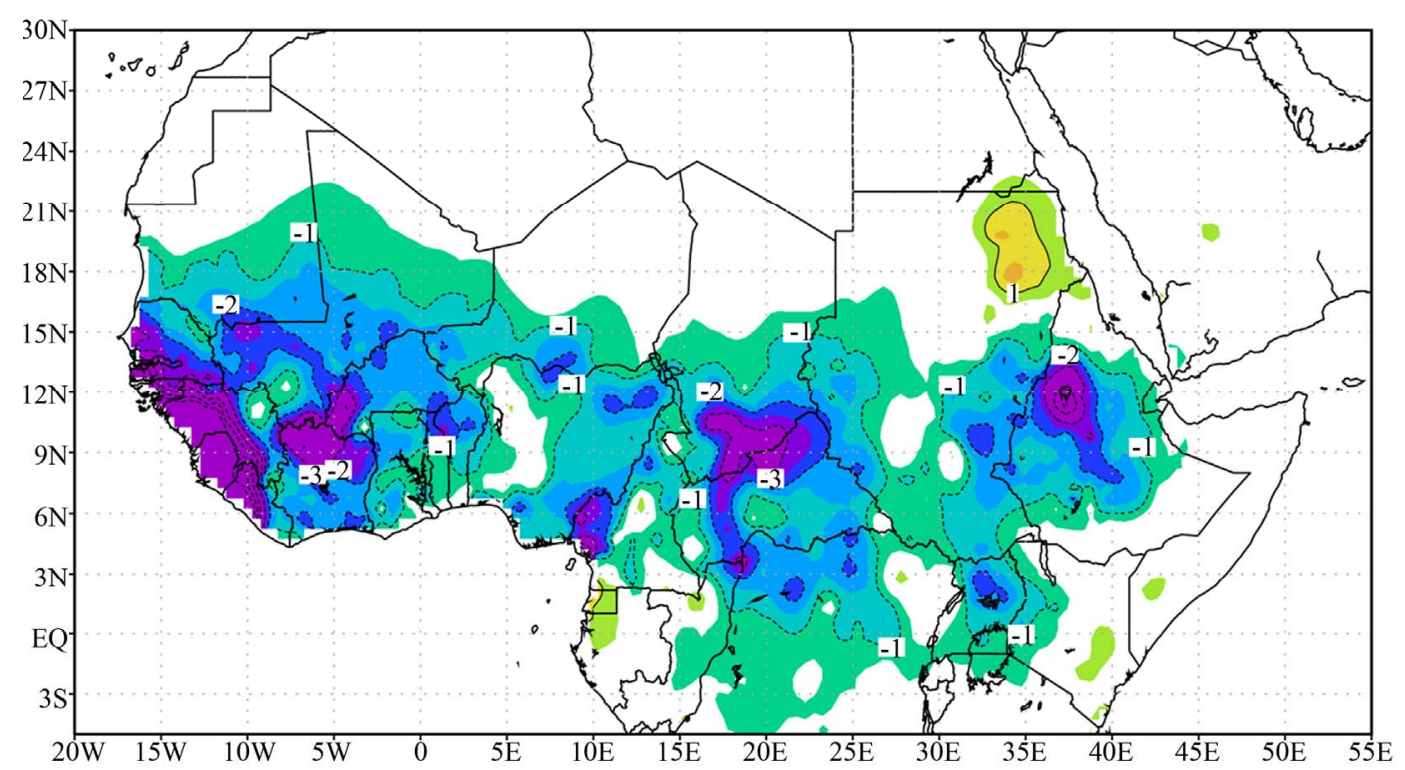

(a)

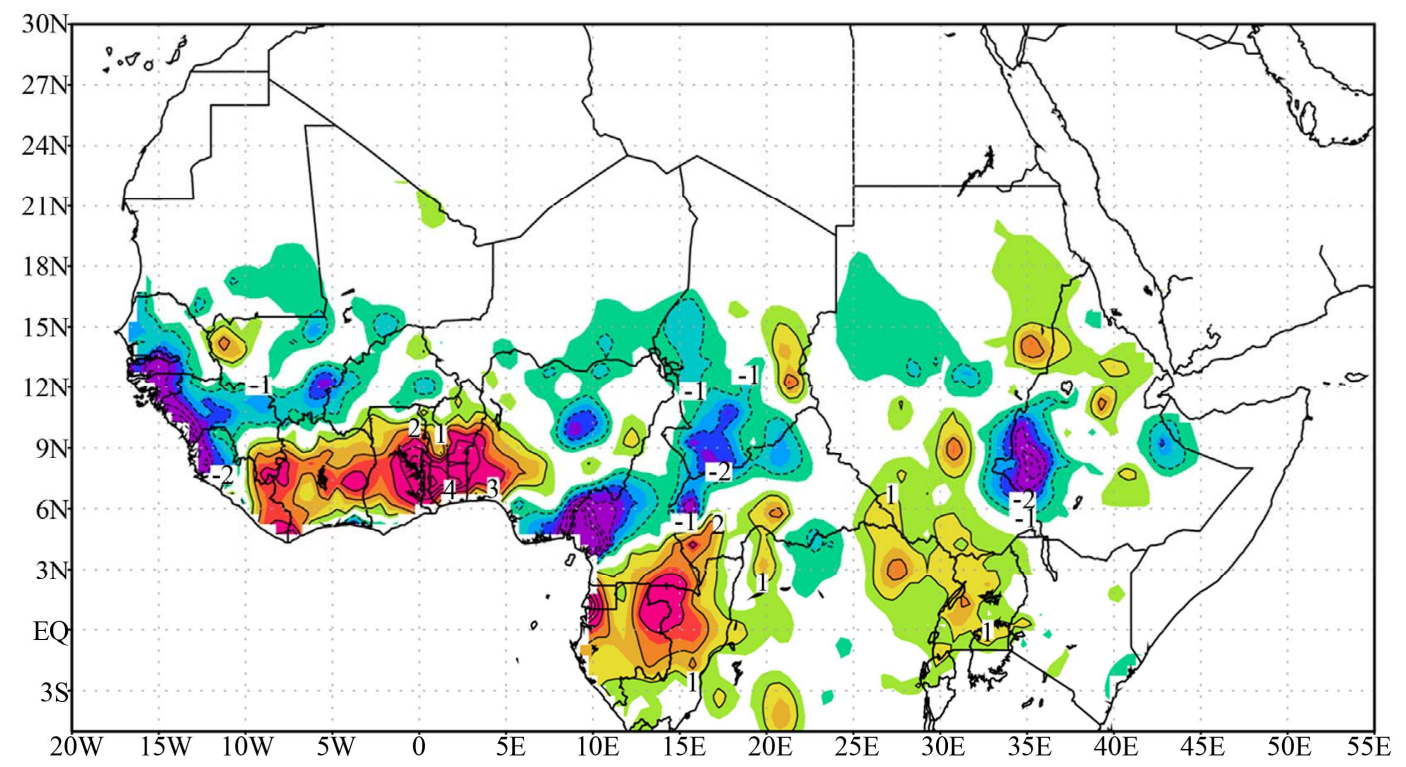

(b)

Figure 5. Composites of Jul-Sep rainfall deviations from the 1950-1999 mean for (a) El Niño e (b) La Niña, during PDO warm phase (WP). Data source: UDEL (ESRL/PSD/NOAA).

out the wet season, that is July-September (Jul-Sep), were considered.

\section{Final Remarks}

It was observed that the WP El Niño events (Figure 5(a)) were associated with negative rainfall deviations for the major part of Equatorial Africa and Sahel during the wet season Jul-Sep. In contrast, during the CP El Niños (Figure 4(a)), the rainfall deviations were positive over Western Africa mainly along the Gulf of Guinea coast and negative over Eastern Equatorial Africa. Burkina Faso and southern part of Niger and Chad were also affected by rainfall reduction not as intense as the warm phase. In general, the CP La Niña episodes (Figure 4(b)) were related to rainfall totals above average over the Sahel and Eastern Equatorial Africa and below average over the Gulf of Guinea coast. In turn, the WP La Niña events (Figure 5(b)) were associated with rainfall below normal practically all over Sahel but rainfall excess over the Gulf of Guinea coast and Equatorial Africa. It is apparent in the El Niño composites of both PDO phases that the ITF latitudinal displacement is short. In the CP La Niña composite (Figure 4(b)), on the other hand, the positive rainfall deviation pattern extended farther north, suggesting a 
more northward ITF position and a consequent northward displacement of the Sahara Desert southern border. The opposite occurred in the WP La Niña composite, in which the ITF remained near the equator, allowing the desert to expand southward and bring severe social and economic impacts to Sahelian countries. [6] and [7] have analyzed the relationship between the movement of the limits of the Sahara Desert with the variability of the low frequency of the configurations of the general circulation of the atmosphere, where the temporal characteristics of the series, such as variance, are evaluated using principal components regression. The results of the analysis of the relationship between the movement of the southern boundaries of the Sahara Desert and the low-frequency variability of the atmospheric general circulation features, particularly those related to the ITF, may be helpful to forecast the advance and retreat of the Sahara Desert and detecting structural changes, characterized by the rhythm of alterations along the time.

Since PDO has entered a new cold phase in 1999, it is expected that the ENSO rainfall impacts be similar to the ones of its previous cold phase (Figure 4) in the next 20 years... if PDO is a real physical oscillation!

In the literature, generalized statements affirming that El Niño (La Niña) episodes produced negative (positive) rainfall deviation in tropical regions are found. Nevertheless, when the regional climates are analyzed, it becomes clear that such statements are not valid, as demonstrated by the above example. It may be possible that PDO is not a regular physical oscillation and their phase's duration may not be predictable and be dependent of large magnitude seismic events, which are rare and random. An important point, however, is that the Pacific SST pattern, once established and recognized, may remain for a relative long (decades) period. Its SST pattern, due to its large areal extension, modulates the global climate forcing the large scale general circulation features, ENSO in particular, to produce distinct regional impacts, depending on the signal and strength of the SST anomalies. This happened with the ITF in the Sahel and may possibly have occurred with other large scale atmospheric structures, such as the Asian Monsoon, convergence zones and subtropical anticyclones centers positioning.

\section{Acknowledgements}

P. S. Lucio was sponsored by a POCTI grant (SFRH/
BPD/5614/2001) from FCT (Portugal), and at the present time he is sponsored by a PQ2 grant (Proc. 302493/ 2007-7) from CNPq (Brazil).

\section{REFERENCES}

[1] S. Hastenrath, "Climate and Circulation of the Tropics," Atmospheric and Oceanographic Sciences Library, Springer, Berlin, 1985. doi:10.1007/978-94-009-5388-8

[2] N. J. Mantua, S. R. Hare, Y. Zhang, J. M. Wallace and R. C. Francis, "A Pacific Interdecadal Climate Oscillation with Impacts on Salmon Production," Bulletin of the American Meteorological Society, Vol. 78, No. 6, 1997, pp. 1069-1079. doi:10.1175/1520-0477(1997)078<1069:APICOW $>2.0 . C$ $\underline{\mathrm{O} ; 2}$

[3] L. C. B. Molion, "Aquecimento Global, El Niños, Manchas Solares, Vulcões e Oscilação Decadal do Pacífico," Climanálise, No. 8 (agosto), 2005. http://www6.cptec.inpe.br/revclima/revista

[4] K. Wolter and M. S. Timlin, "Measuring the Strength of ENSO-How Does 1997/98 Rank?" Weather, Vol. 53, No. 9, 1998, pp. 315-324.

http://www.cdc.noaa.gov/people/klaus.volter/MEI/mei.ht $\mathrm{ml}$

doi:10.1002/j.1477-8696.1998.tb06408.x

[5] E. Kalnay, M. Kanamitsu, R. Kistler, W. Collins, D. Deaven, L. Gandin, M. Iredell, S. Saha, G. White, J. Woollen, Y. Zhu, A. Leetmaa, R. Reynolds, M. Chelliah, W. Ebisuzaki, W. Higgins, J. Janowiak, K. C. Mo, C. Ropelewski, J. Wang, R. Jenne and D. Joseph, "The NCEP/ NCAR Reanalysis 40-Year Project," Bulletin of the American Meteorological Society, Vol. 77, No. 3, 1996, pp. 437-471.

doi:10.1175/1520-0477(1996)077<0437:TNYRP $>2.0 . C O$ ;2

[6] P. S. Lucio, L. C. B. Molion, F. C. Conde and M. L. D. de Melo, "A Study on the West Sahel Rainfall Variability: The Role of the Intertropical Convergence Zone (ITCZ)," African Journal of Agricultural Research, Vol. 7, No. 14, 2012, pp. 2096-2113. doi:10.5897/AJAR11.627

[7] P. S. Lucio, L. C. B. Molion, C. de A. Valadão, F. C. Conde, A. M. Ramos and M. L. D. de Melo, "Dynamical Outlines of the Rainfall Variability and the ITCZ Role over the West Sahel," Atmospheric and Climate Sciences, Vol. 2, No. 3, 2012, pp. 337-350.

doi:10.4236/acs.2012.23030 